\title{
On projection screens
}

This content has been downloaded from IOPscience. Please scroll down to see the full text. 1919 Trans. Opt. Soc. 2134

(http://iopscience.iop.org/1475-4878/21/1/303)

View the table of contents for this issue, or go to the journal homepage for more

Download details:

IP Address: 147.188.128.74

This content was downloaded on 25/08/2015 at 08:53

Please note that terms and conditions apply. 


\section{ON PROJECTION SCREENS \\ By CHARLES W. GAMBLE, M.Sc. (Tech.)}

(Department of Photographic Technology, College of Technology, Manchester)

MS. received, 16th fuly, 1919. Read and discussed, 16th October, 1919

Although screens for receiving projected images may be regarded as optical devices, and, reasonably, devices of a delicate nature, it is perhaps singular that there has been until recently little or no attention paid to investigating the conditions which determine their efficiency.

By far the largest use of projection screens occurs in the cinematograph theatres, which are so widely distributed. The degree of success which these places of amusement attain is largely determined by the provision which is made for the comfort of their patrons-comfort in the broadest sense of the term-and to the fulfilment of this condition the efforts of the best managements are continually devoted. Now 'comfort' in one important respect is largely conditioned by the degree to which all causes of visual fatigue or irritation are eliminated. Comfort is not alone, as many might think, the services of polite attendants, quietude, soft chairs and pleasing decorations. To secure pleasant viewing of any form of projected picture the chief thing is to utilise for the screen the most thoroughly diffusive surface, whilst economy of the energy used in the lamp house of the projector requires the employment of a surface having high reflective power. The employment of arcs of high as against medium amperage means considerable personal discomfort and inconvenience to operators from the heat (especially in view of the confinement which tends to follow the fulfilment of the rigid conditions imposed by the Local Authority as to safety) and increased risk of damage to the film under projection. Any inefficiency in the reflective capacity of the screen means a corresponding increase in the energy required in the arc to secure the necessary brightness of image and an extension in this direction involves extra cost in the working expenses of a cinematograph theatre. In consequence, attention has been given to the subject but what improvements have been made have been the results of 'practical' tests rather than quantitative methodical investigation. Perhaps the worst examples of projecting screens (indeed projection apparatus and projection generally) are to be found in the lecture rooms of Colleges devoted to the teaching of Science, where neglect of the whole subject seems to suggest that optical problems belong to that category of things existing purely in the realms of abstract ideas.

It is proposed in this paper to deal with the subject mainly in its relation to cinematography, but the observations will apply generally to ordinary static projection.

The advantage of exact information on the problem of what is the best form of projection screen and indeed on projection screens generally has recently been 
supplied by a gentleman who is a member of this Society, Dr P. G. Nutting, who in an able paper records the result of some investigations into the subject ["Projection and Focussing Screens," Trans. Ill. Eng. Soc. I I (1916), 92], and some little time ago when Service requirements in the Royal Air Force made it necessary to pay attention to the subject of screens for cinematography, Dr Nutting's paper proved of considerable value and frequent reference will here be made to the information which he has provided. Experiments had however been made of a comparative character before I had read the communication of which mention has been made.

It will not infrequently be found that the best optical conditions for a given projection are not always fulfilled, sometimes indeed cannot be fulfilled, and there is, moreover, a tendency on the part of operators to employ arcs far more powerful than is actually necessary. In many instances the amperage with a given size of carbons is far below what it might be. Although it has been shown that carbons will burn satisfactorily with a current density of 0.2 to 0.3 amperes per square $\mathrm{mm}$. of the positive carbon it will be found that less than one-half of these amounts are taken and the reduced amperage means a less efficient crater and also what is an item of importance where there is a large consumption, the proportionately higher loss on rejected ends of the rods. Frequently, the argument in favour of the low amperage is the rather naively practical one, viz., that it saves the labour of frequently recarboning. Further, the carbons are often badly adjusted. The sum of these things (each apparently small) makes for an inefficiency which is a real loss.

The essential condition which must be fulfilled by any screen which is to receive a projected image is that the whole area must be a plane surface; strictly speaking, this means that the screen will be smooth. Broadly speaking, however, the screen may be in the ordinary way flat and yet present an appreciable 'grain' which means that it is not smooth. This quality tends to detract from its ability to render fine gradations sharply, but provided that the grain is not too pronounced it does not sensibly affect the rendering of the finer details of the picture. Some of the proprietory screens which have been offered possess this 'grain' which has even been claimed as an advantage, indeed, Dr Nutting himself has postulated as an ideal projection screen, a mirror the front face of which is composed of minute hexagonal facets each of which is a concave mirror of a particular angle. Screens in practice range from a surface of smooth white linen or cotton with a highly diffusive surface to the more or less regularly reflective surface formed by the spread of a metallic aluminium paint upon a smooth white ground.

To compare the efficiency of the chief surfaces a large frame was covered with fine white Bolton sheeting and upon this was formed a composite screen consisting of strips 6 by $\mathrm{I}$ feet arranged as follows:

(a) Plain white Bolton sheeting;

(b) Finest white calico;

(c) Duresco, a white composition coated on Bolton sheeting;

(d) Aluminium paint direct on Bolton sheeting; 
(e) Aluminium paint on a substratum of Duresco on Bolton sheeting;

(f) A typical proprietory screen of the white diffusive type;

(g) A proprietory screen consisting of a fabric with a fine 'grained' surface with a finishing coating of aluminium paint.

This screen was then tested under.strictly practical conditions, that is to say, films of different character were projected and the effects were judged by an audience who were acquainted with the practical requirements, but who were themselves unacquainted with the nature of the different surfaces. The walls of the theatre were very dark and all extraneous light was excluded. The throw was 35 feet and the size of the experimental picture projected was 4 feet 6 inches with a current of from $17^{-25}$ amperes flowing in the arc. The final judgment was that the Duresco gave the most pleasing result but that the picture brightness fell below that of the aluminium paint on Duresco as might be expected. There was a distinct falling off in brightness and in general quality in $(a)$ and $(b)$ but $(b)$ was the better of the two. The tests which were very carefully carried out were after all only qualitative but they were strictly comparative and they dealt, moreover, with those materials which were in general use. Since it is not possible to secure and to maintain flatness by means of any form of rollable or stretched fabric and as flatness is essential for the desired result the most efficient screen, judging from these experiments, would be a specially prepared flat wall with a perfectly smooth surface properly treated with white Duresco or similar material which should, in addition, receive a final dressing of aluminium paint if the maximum luminosity be required. Actually this accords, in many instances, with the best practice. The drawback, however, to the use of aluminium as with all highly reflective surfaces, is that it limits the angle of uniform brilliancy so that observers seated at the margins of a wide theatre if they were near to the screen would be at a disadvantage as compared with those who were seated in or near the central line joining the screen and the projector. No surface painted screen, however, is permanent, particularly when exposed to the atmosphere of an ordinary theatre. Generally, the white assumes a yellow tinge and there is formed in addition a film composed of particles of dust and of tarry matter from the plentiful tobacco smoke daily produced by portions of the audience. These changes reduce the reflective power of the screen and in consequence the brilliancy of the projected picture, a small quantity of dust being very effective in this respect. On the other hand the renewal is quickly effected and at a relatively low cost and the original cost not being high the screens are altogether economical. While the reflective power of the metallic screen is high the glare due to the lack of perfect diffusivity does cause to many considerable visual discomfort, and for this reason as well as for the one given, viz., the restriction of angle of uniform illumination, they are open to real objection.

An interesting experiment was tried in which there was deposited metallic silver on the matt surface of a thin sheet of ground glass which was used as a screen, the natural surface of the glass facing the projector. So far as the formation of the image was concerned the screen was quite effective but the brilliancy was low, far lower indeed than the surfaced aluminium screen. 
In his paper, Dr Nutting points out that the ideal screen should reflect all the light uniformly thrown upon it within a given angle of, say, 30 degrees from the normal and postulates that, as a measure of the 'diffusive efficiency' of any screen, the ratio of the light which is reflected within this given angle to the total light which is reflected. If this be adopted the total efficiency of some reflecting materials can be calculated from photometric data and the results of some of these determinations are reproduced from Dr Nutting's paper below, calculating the 30 degrees diffusion efficiency, total reflecting power and 30 degrees total efficiency:

\begin{tabular}{|c|c|c|c|c|}
\hline \multicolumn{2}{|c|}{ Screen } & $\begin{array}{l}30^{\circ} \text { diffusion } \\
\text { efficiency }\end{array}$ & $\begin{array}{l}\text { Reflecting } \\
\text { power }\end{array}$ & $\begin{array}{c}\text { Total } \\
\text { efficiency }\end{array}$ \\
\hline Magnesium carbon & block ... & 0.25 & 0.87 & 0.22 \\
\hline Aluminium paint, & yroroid $B$ & 0.52 & 0.25 & $0 . \mathrm{I}_{4}$ \\
\hline Becker compound & $\ldots \quad \ldots$ & $0 \cdot 54$ & 0.63 & 0.34 \\
\hline Ground mirror & $\ldots$ & 0.69 & 0.92 & 0.64 \\
\hline Ideal screen,$\ldots$ & $\ldots$ & 0.9 to 1.0 & 0.92 & - \\
\hline
\end{tabular}

(Note. The "icleal" screen of Dr Nutting is defined as follows: a mirror, the front face of which is composed of minute hexagonal faccts, each of which is a concave mirror of just sufficient cliameter to tefract light at a maximum angle of $I_{5}$ degrees with the axis.)

The reflecting power of a screen is the ratio of the light totally reflected to the light totally incident, and the total efficiency is the ratio of the light which is reflected within the angle of 30 degrees of the normal to that which is totally incident.

Amongst the materials which were photometrically tested by $\mathrm{Dr}$ Nutting, some of the constants of which are given in the table above, is a glass mirror silvered on the back and then ground on the remaining or exterior surface. On reading the paper the figures appeared to be so good that it was decided to experiment at once with the material. At angles greater than 30 degrees there is with this mirror a marked falling off in the light reflected but the efficient angle is large. For the purposes of a preliminary trial a screen was made of ordinary $2 \mathrm{I} \mathrm{oz}$. sheet glass, silvered by deposition and fine sandblasted on the exterior face and this proved itself to be entirely successful. On placing this screen temporarily in contact with the ordinary fine white matt projection screen then in use, the increase in brilliancy was startling.

Mechanical considerations required that if screens of this nature were to be employed of large size; that they must be much thicker than is the case with $2 \mathbf{I ~ o z}$. glass. With 2I oz. glass the reflecting and diffusing surfaces are only about $0 \cdot 1$ inch apart. It did not appear correct to make the assumption that if this distance were increased, say, to $\mathrm{I} / 4$ inch that the effect would be equally satisfactory but the reasonable doubt in this respect was removed by a further trial with a screen of greater thickness. It was then decided to instal a screen of reasonable dimensions for the small theatre where the main demonstrations were given and to this end one of 6 feet 6 inches by 4 feet 6 inches was made. This screen (which was mounted in a stout black wooden frame) was given a lengthy practical trial and proved itself to be, by a general consensus of opinion, entirely satisfactory. It was found that with the same film equal brilliancy resulted from the expenditure of from $1 / 2$ to $2 / 3$ the current consumption. There was shown to be one very striking 
difference in the appearance of pictures projected on the mirror screen as compared with the ordinary opaque screen which is difficult to explain as it is difficult to demonstrate, except to those who can actually see the comparison. The pictures certainly have more of that indefinable quality 'life'-even the shadows have the quality.

An endeavour was then made to improve the effect by using a special form of obscured glass prepared by a method of fluoric acid etching. In this glass the 'surface' consists of a series of irregularly shaped very shallow cavities, the diffusivity being much less than that of ground glass. When silvered on the plane side and used as a screen with the rough surface towards the projecting lens the effect was extremely satisfactory so far as regards the brightness of image but the angle of view for uniform illumination was very small.

An objection was raised by some who had witnessed the early trials that whilst the screen would be good for exhibiting the images from films which showed normal or ordinary contrasts it would be objectionable for those where the contrasts were considerable. The high lights, it was averred, would be too bright. This seemed to be a reasonable objection, for since absolute brightness of high lights was concerned and the pleasantness or the reverse of the visual experience would be the final test, it did not seem fair to argue that the ratio of brightness of tones by which contrast is measured would be the same as for an opaque screen. It is customary with some operators under such conditions as I have stated to lower the illumination by decreasing the current flowing through the arc, a plan which is not entirely satisfactory. It suggested itself to me after some consideration that the simplest way to overcome the difficulty would be to place in front of the projecting lens a neutral tinted glass screen of low optical 'density' (density $=\log _{10}$ opacity) and this on trial was found to be perfectly effective. The effect is to dim uniformly the picture-the relation of the tones remains the same, but the absolute brightness of the high lights is lessened and this fact constitutes the effectiveness of the device. A very low density suffices and it was not found necessary to use a screen with optically worked surfaces. Actually, the quality of the screen used was about equal in flatness, and in freedom from flaws, to patent plate. This device-which appears to be of a useful character-is recommended to the attention of makers of projectors who might supply such an attachment at a low cost.

A matter of some importance when considering the general efficiency of projection screens-and this applies to all forms of screen-is the nature of the surroundings. The screen should always have a border of appreciable width and of low luminosity which condition is best secured by the use of a black fabric. This serves to isolate the projected picture from its surroundings-which is the function of any form of frame-and a device of this character is quite necessary to secure concentration of the attention of observers on the picture itself-and by its low brightness accentuates contrast between the picture and its frame. It is important also to see for these reasons (quite apart from the irritation which is caused by the reverse) that the picture fills the frame-it should not be less than the limit of the screen's size, nor should it overlap. In good cinematograph 
projection this occurs; the pictures are standard and the dimensions of the screen are in this proportion. There are of course other optical and mechanical conditions which must be fulfilled in order that the projected picture may produce a pleasant sensation, such as constancy in the lamphouse and steadiness in the projector (the future projector will probably be more strongly built and mounted on a much better foundation than usually obtains now), absence of mechanical defects in the film, and uniformity in their photographic qualities. But, in the sum of the different factors which make for goodness that concerned with the screen has a high figure of value and whether it be a still or a moving picture the necessities are the same.

Whilst there are practical difficulties to be overcome in the supply of the new mirror screen formulated, of a sufficiently large size to fulfil the requirements of important picture theatres, this does not apply to many other places where projected pictures are used. This observation applies notably to Colleges and Schools where as a rule the methods and the conditions of the system of projection leave much to be desired and it is hoped that this simple communication may serve the useful purpose of drawing attention to the subject. 


\section{DISCUSSION}

The President (Prof. F. J. Cheshire) drew attention to a paper on optical projection screens, by $H$. Lehmann, read before the German Physical Society in 1908. Some of the results obtained are illustrated in the following diagram.

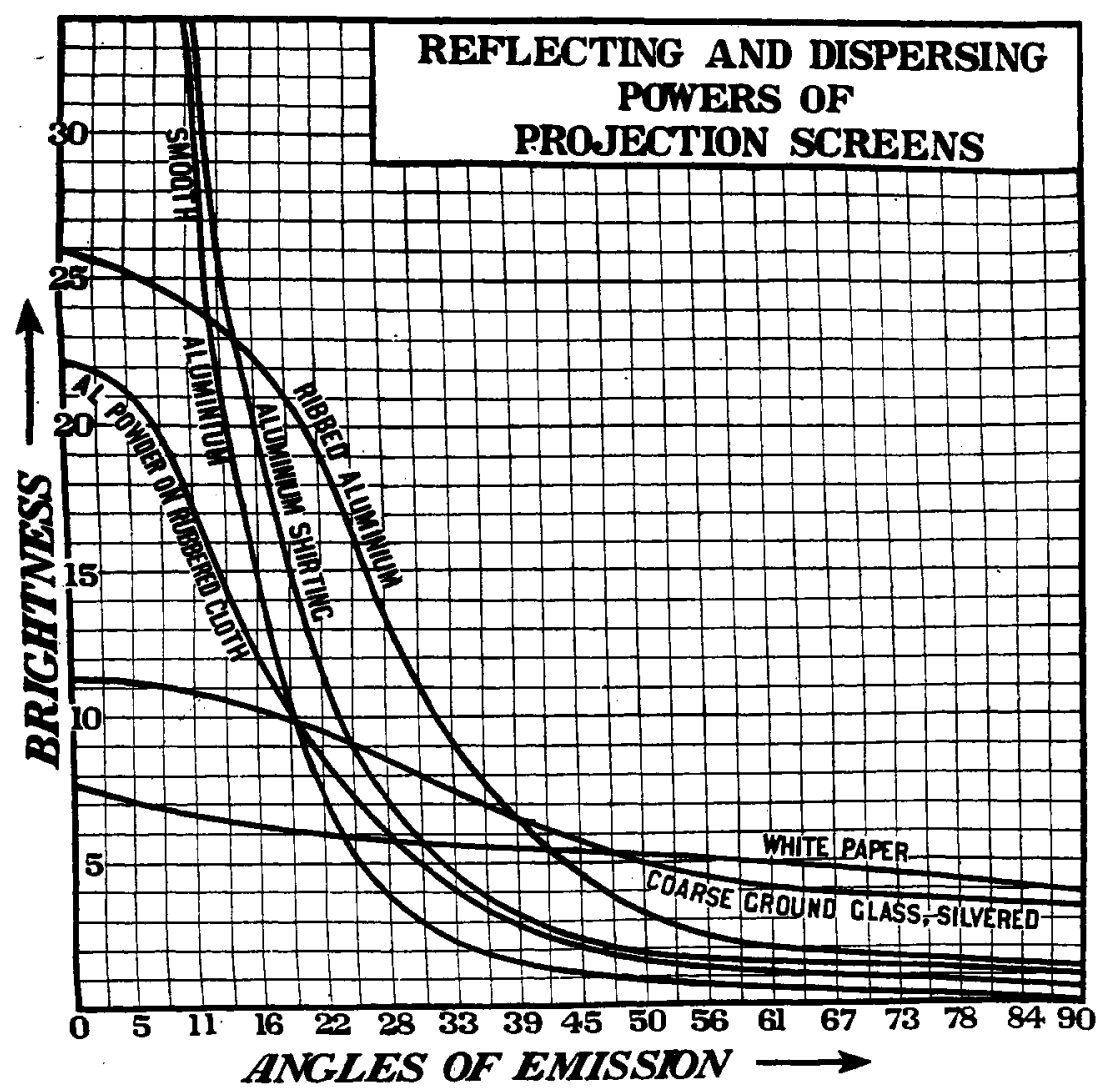

The screens were illuminated with normally incident light throughout, and the intensity of the light reflected at angles to the normal, varying from zero to $90^{\circ}$ determined with a photometer. In the diagram therefore "the abscissae represent the magnitudes of the angles of emission or angles of obliquity at which the screen picture is viewed, whilst the ordinates give the relative screen luminosities."

The author communicated the following reply.

I had not had the advantage of seeing Lehmann's paper until my attention was drawn to it by the President's remarks. 